\title{
From the Inside, Out \\ Use of Optical Measuring Techniques for Wind Turbine Development
}

\author{
A. Stanley ${ }^{1 \mathrm{a}}$, M. Klein ${ }^{2 b}$ \\ ${ }^{1}$ GOM UK \\ ${ }^{2} \mathrm{GOM} \mathrm{mbH}$ \\ aa.stanley@gom.com, bm.klein@gom.com
}

Keywords: Optical measurement, 3D scanning, Photogrammetry, DIC

\begin{abstract}
Current trends in the wind turbine industry demand that manufacturers and related research facilities increase development efficiency whilst minimizing production costs. A key component developed is the blade, which needs to efficiently capture the wind energy whilst being able to survive severe weather conditions. More recently larger blades have been used, where main advantages include an increase in wind capture efficiency, a reduction in the installation and reduction in maintenance costs per MW. This paper outlines the main principles behind optical measurement techniques employed, influencing factors for using this technology, and presents the importance of the results achieved thus far and describes ongoing development activities.
\end{abstract}

\section{Introduction}

In order to better understand the local material and component response and the global behaviour of wind turbines, GOM's Optical Measuring Techniques were employed. Components were measured for the determination of raw material parameters, component response under loading, as well as in 3D quality control applications.

\section{Component Deformation Measurement}

With larger blades being implemented, use of lightweight material affords reduced inertial forces on the drive train. However, consideration needs to be taken of non linear failure modes resulting from increased flexibility [1].

The ARAMIS 3D deformation measuring system uses digital image correlation. Using a black and white speckled deterministic pattern, grey value distributions are calculated for a large amount of small subsets in each camera image and provide sub-pixel accurate positions about corresponding points between all images (Fig.'s 1 and 2).

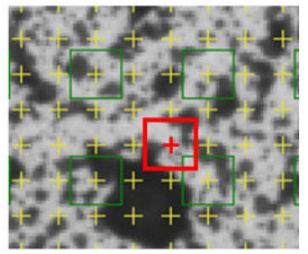

Figure 1: Undeformed patterned specimen with regular subsets

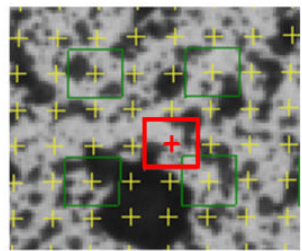

Figure 2: Undeformed patterned specimen with, now with irregular subsets

The mathematical model of the sensor setup, the digital image correlation method and a triangulation calculation are combined to derive highly accurate $3 \mathrm{D}$ coordinates. Subtracting the surface information in all loading stages in 3D space provides precise $\mathrm{X}, \mathrm{Y}$ and $\mathrm{Z}$ displacement values.

Strains are calculated considering the component's geometry and plasticity theory. As the image acquisition is time-based, even $3 \mathrm{D}$ velocities and strain rates are automatically achieved. 


\section{Out of Plane Flexure on light weight Internal Components}

Composite material is essential for modern wind turbine blades due mainly to its high strength-toweight ratio. Understanding deformation of the load carrying spars that run the length of the blade is a key step in understanding blade behaviour. Past research has shown how these structures are subject to out of plane flexure due to the Brazier effect [1], and the optical measurement technique has been used in conjunction with coupon spar specimens under flexure to analyse how this out of plane deformation affects the anisotropic blade structure [2].
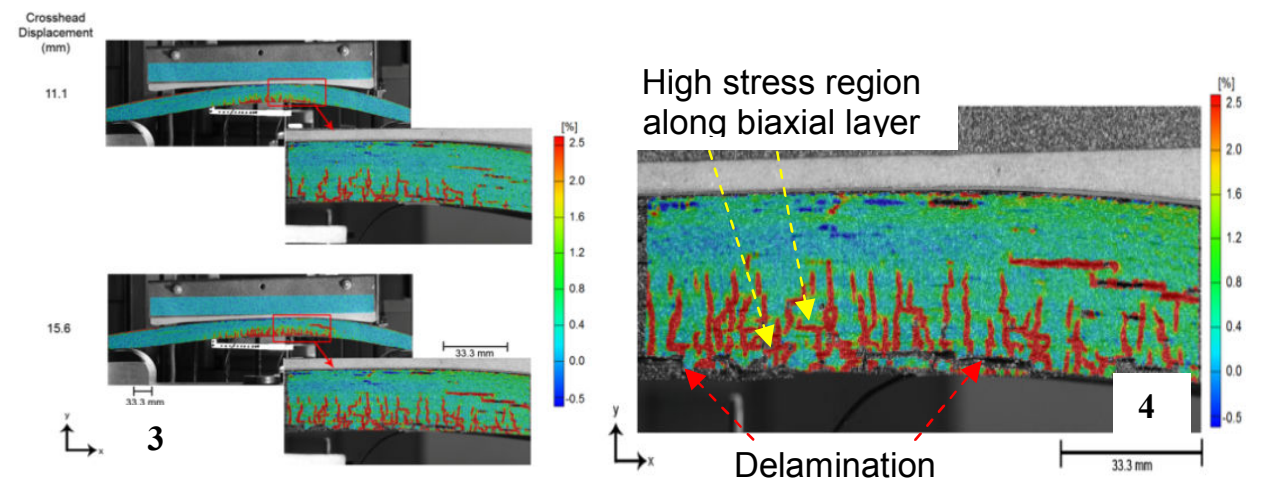

Fig.: 3) bend test on composite turbine blade material; 4) Display of biaxial strain and delamination in the vicinity of matrix cracks.

The measurement results showed numerous delaminations, mainly at the highest bending strains (Fig. 3). Closer examination shows that at high strains along the biaxial layers, with cracks present, the biaxial layers themselves still hold the majority of the bending load (Fig. 4) [2].

\section{Large scale tests and $F E$ verification:}

The measurement principle remains constant for all test types, only here, a 34 meter glass fibre core of a wind turbine blade was bended to failure, where a measurement area of $3 \times 3 \mathrm{~m}$ was set up (Fig. 5).
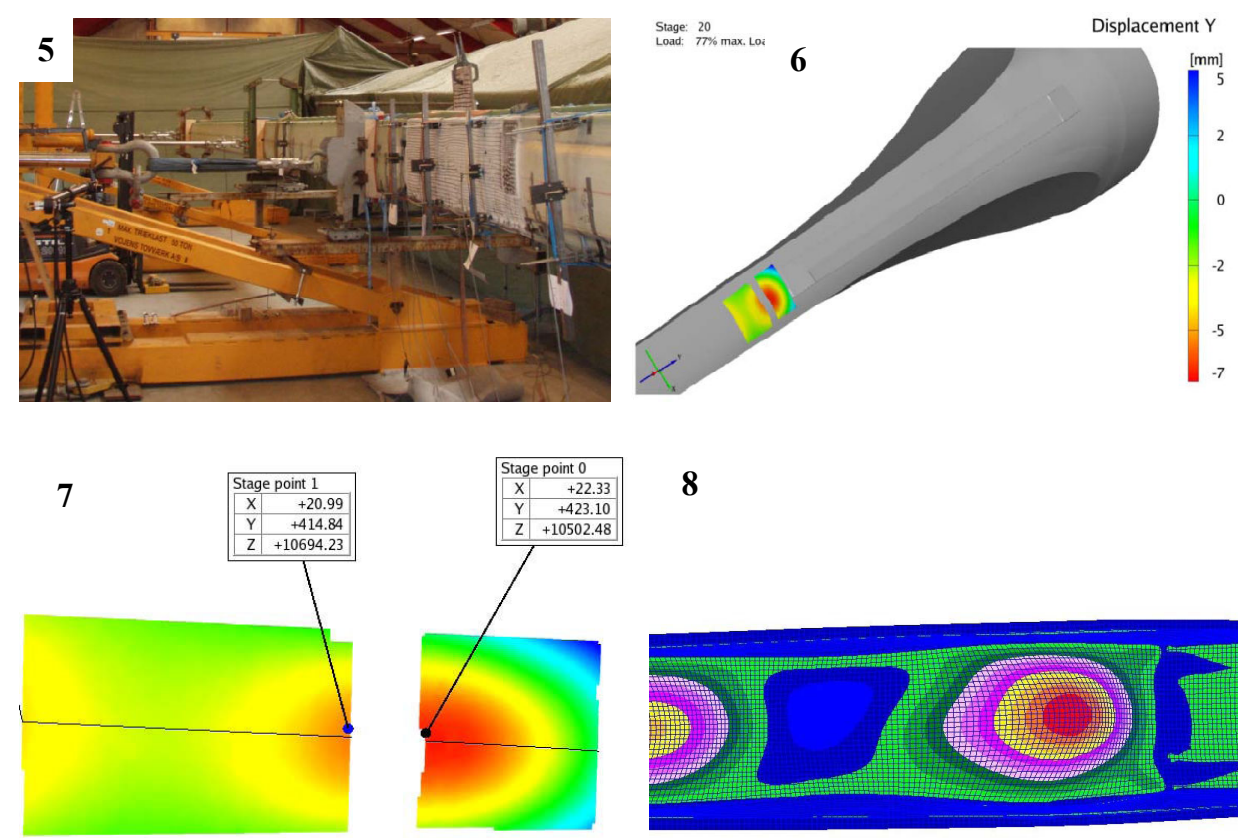

8

Fig. 5. Turbine blade test set up; Fig. 6. Coordinate system for Aramis plot on CAD dataset; Fig. 7.Aramis results for bending effects of blade surface; Fig. 8; Result from FE simulation.

The results obtained give integral information regarding bending effects on the surface of the blade (Fig. 7). However, it goes one step further than that in being used for the integrated verification of simulations (Fig. 8). 
Furthermore, it is possible to import CAD datasets, which in this case have been used to set a coordinate system for the measurements results (Fig. 6).

\section{Wind turbine off-shore mounting}

Using the GOM TRITOP coordinate measurement technique, a measurement object is recorded with a high-resolution digital camera.

For the setup of offshore wind turbines the components are built on land then are tugged to their destination ashore and where the foundations are anchored to the sea bed (Fig. 9). For mounting the lowest tower segment, 120 steel bolts are recessed in the concrete foundation, positioned in two circles with a diameter of approx. 4 meters (Fig. 10).

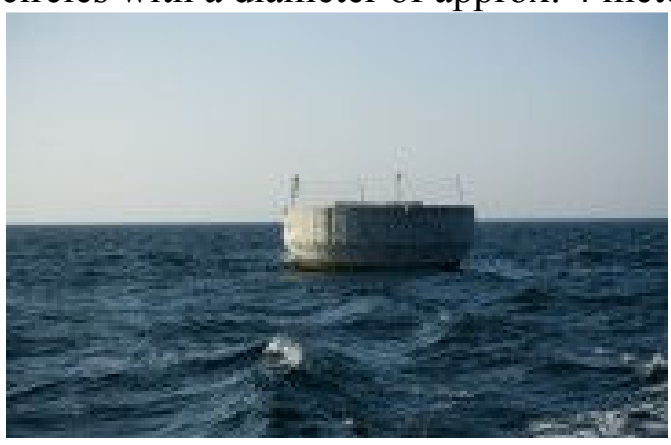

Fig. 9: Offshore anchored concrete foundation

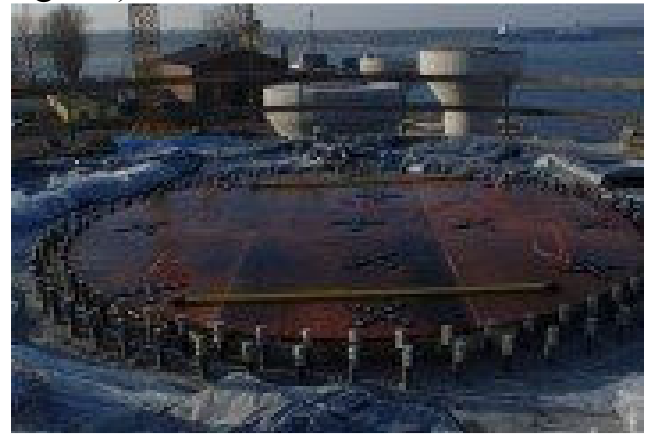

Fig. 10: Position of mounting bolts in the concrete foundation and preparations for the measurement

The mounting bolts in the concrete foundation have to be verified to the required accuracy of $1 / 10$ millimetre. The knowledge about the $3 \mathrm{D}$ positions of the bolts enables the verification of these against the nominal positions directly after the completion of the foundations ashore as well as after the anchoring on high seas (Fig. 11).
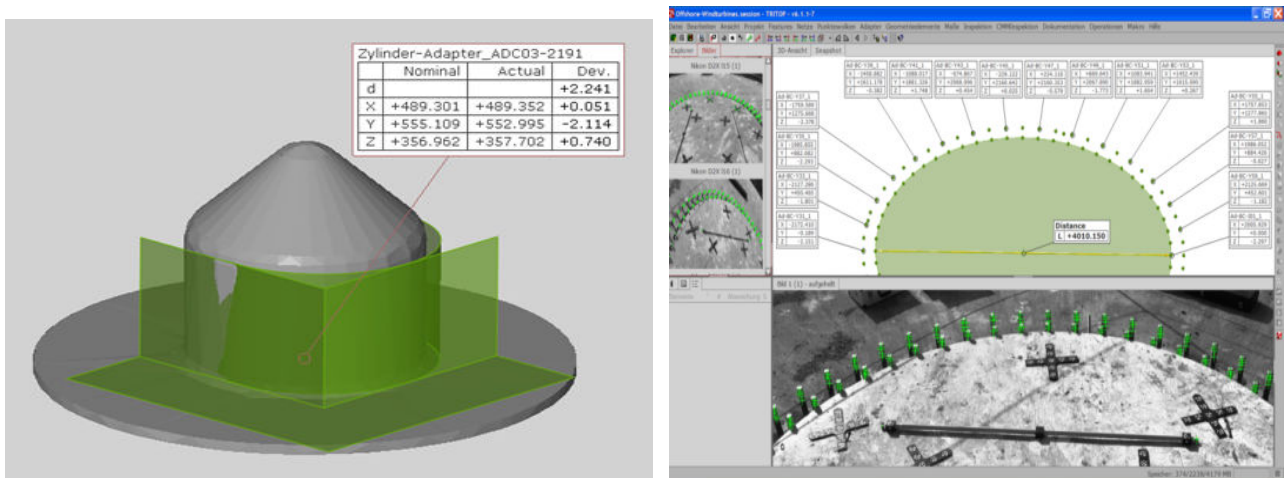

Fig. 11: Inspection of a single and all 120 mounting bolts positions.

Falsely positioned or tilted mounting bolts can be identified quickly and clearly with the required accuracy eliminating problems before starting the mounting process [3].

\section{Wind operation analysis}

The GOM PONTOS approach is one of point target tracking. It uses a calibrated pair of cameras to triangulate the $\mathrm{X}, \mathrm{Y}$ and $\mathrm{Z}$ coordinates of the centres of circular dot targets with an accuracy of approximately $1 / 50$ pixel with a nominal accuracy of 30 microns per meter of field of view (Fig. 12). The coordinates of each target at a reference condition are subtracted from the current coordinates in each test image to compute the 3D displacements.

The optical system setup for measuring deflections on a wind turbine is seen in Figure 13 [4, 5] - targets are recorded at a speed of $100 \mathrm{~Hz}$. 

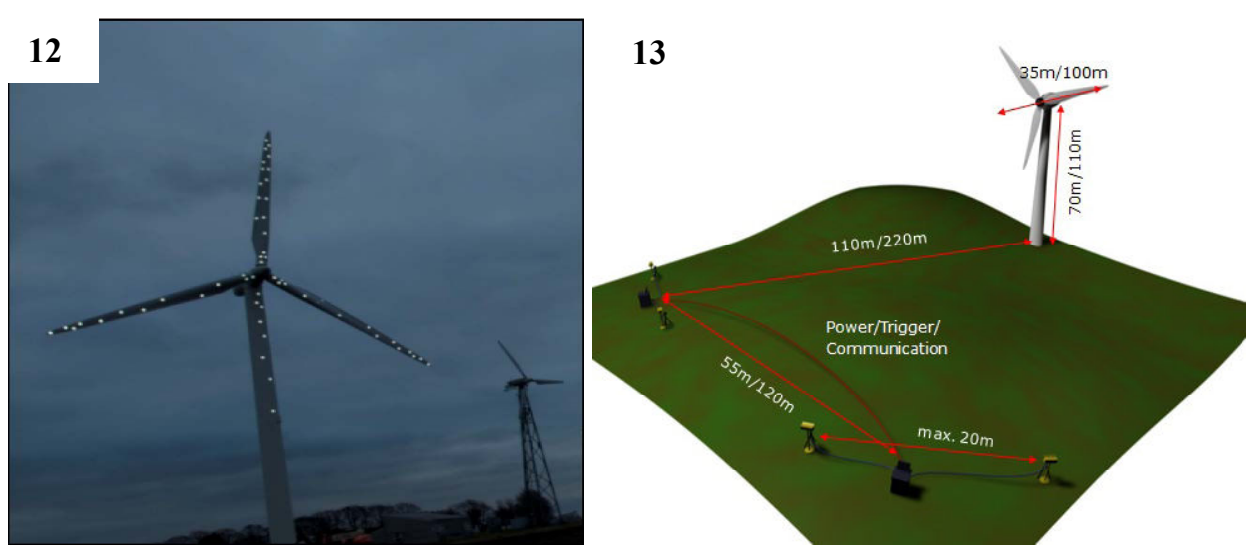

Fig. 12. Experimental layout of camera system; Fig. 13, Measuring targets on wind turbine.

The initial measurement data shows all motion relative to the camera system, where a coordinate system transformation is applied to set the global coordinate system relative to the turbine.

Emergency Stop
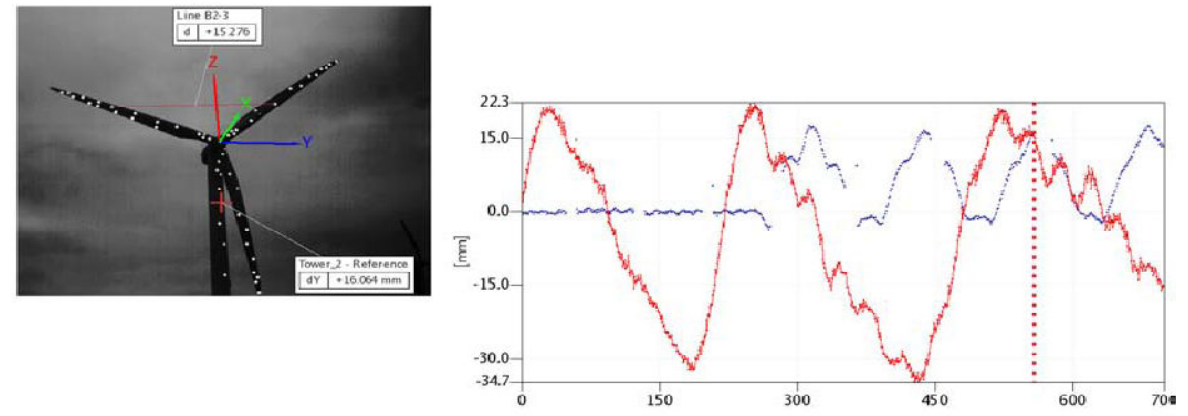

Deformation (Vector)

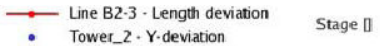

embrake_start.14_trajectories.dyn

Date: 18.12 .2007

Stage 559
Time $5.58 \mathrm{~s}$

\section{PONTOS 14}

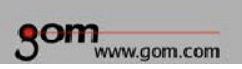

Fig. 14: Tower versus blade deflection during an emergency stop Fig. 15: Vector plots that can be animated during review of captured data show 3D resultant displacements for three similar points on each blade. The phases are very orderly, with some amplitude variations (next page).

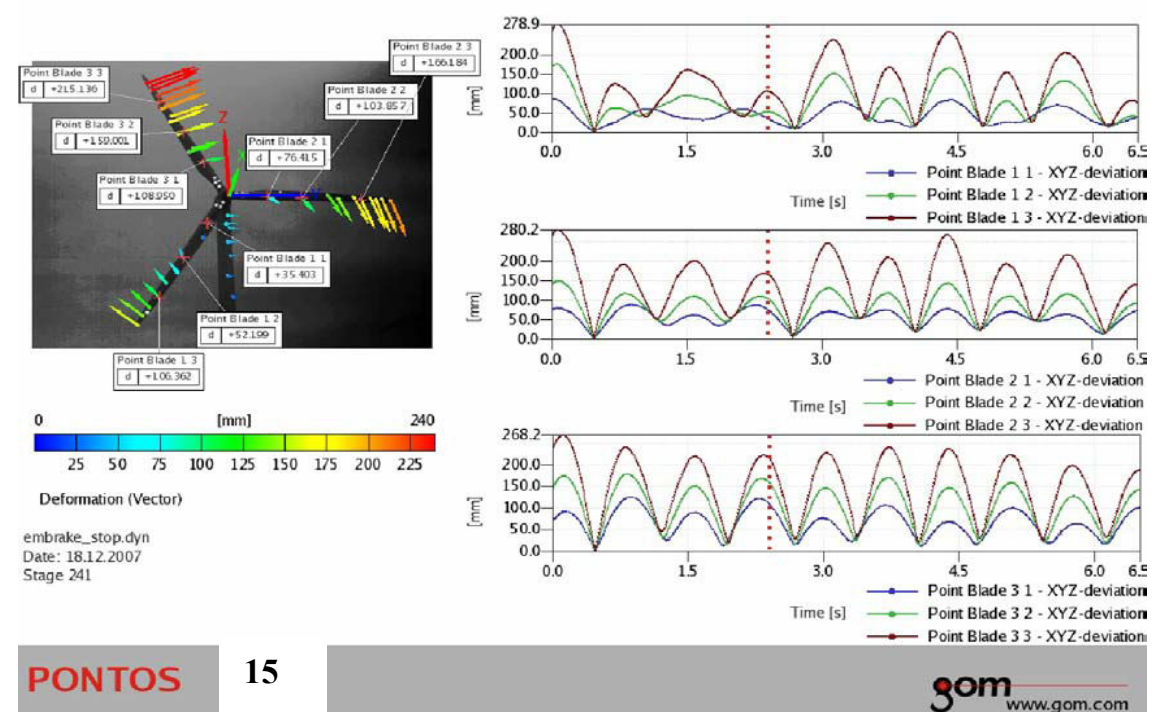




\section{Summary:}

The utilisation of optical measuring systems contributes strongly in the process of development and manufacturing of wind turbines. Material parameters and components' response are determined and used for the development of new material models and the verification of FE models. 3D digitizing and coordinate measurements are part of the quality control, calculating the full field deviation to CAD models and determining quickly areas where changes need to be done. Further assembly applications are served and full-scale deformation and vibration analysis can be carried out [6].

\section{References:}

[1] Jensen, F: Ultimate strength of a large wind turbine blade. Technical University of Denmark (2008);

[2] Puri, A et al: Analysis of Wind Turbine Material using Digital Image Correlation. Imperial College London (2009).

[3] Radke, M: Mobile Optical Coordinate Measuring Technology Used in Offshore Wind Turbines Setup. I.T.A., (2009)

[4] Schmidt Paulsen, U., Erne, O., Klein, M: Modal Analysis on a $500 \mathrm{~kW}$ Wind Turbine with Stereo Camera Technique. I.O.M.A.C., (2009)

[5] Schmidt, T., Tyson, J: Some Common and Not So Common Applications of 3D Image Correlation. Proceedings of the GOM International User Meeting, Braunschweig, Germany, (2007).

[6] Erne, O., Friebe, H., and Galanulis, K., Is it possible to replace conventional displacement and acceleration sensor technology? Solution methods using optical 3D measuring technology. GOM white paper, (2007). 